\title{
EDITORIAL
}

\section{The Making of a Modern Day Surgeon}

In contrast to surgeons of the last century, modern day surgeons are expected to have sound clinical and surgical skills, possess excellent inter-personal communication, be managers and team players, and have training in research.

This is a tough ask of training programs that are under constant pressure to pack basic and higher surgical training into reduced training years, and where, in some countries, work hours have been reduced to 40 hours per week.

The call of the hour must now be target oriented training and highly skilled mentoring of surgical trainees. Furthermore, the need for continued surgical education as consultants will help sharpen an ever evolving surgical arena grounded in minimal invasion, preservation of organs and maximal restoration of anatomy and physiology. As communicators, the expectations are high as we deal with patients armed with a barrage of information from the world-wide web, communicate with surgical juniors and nurses, and negotiate the best deal for our patients with hospital administrators.

Knowledge of research is expected of all trained surgeons as more and more of our patients demand the best evidence for the multitude of treatment modalities that are currently on offer - the result of these changes will be a smarter, sharper and more focused surgeon.

With these goals in mind, the editorial team has commissioned a series of articles written by acknowledged experts in their field. The current issue has articles on surgical education and basic statistics. We very much hope that you, our readers, will enjoy this and future issues of the journal and provide us with feedback on the way forward. 